\title{
The analysis of factors and motivative aspects promoting and hindering the implementation of precision farming technologies
}

\author{
A.S. GUSEV \\ Department of Land \\ Management \\ Ural State Agrarian \\ University \\ 620075, Ekaterinburg, \\ Karl Liebknecht str., 42 \\ RUSSIA \\ N.V. ZIABLITCKAIA \\ Department of Economics, \\ Management and Law, \\ South Ural State \\ University, Chelyabinsk, \\ av. Lenina, 76, 454080 \\ RUSSIA
}

\author{
O.I. BETIN \\ Federal State Budgetary \\ Scientific Institution All- \\ Russian Research Institute of \\ Fisheries and Oceanography. \\ 107140, Moscow, Verkhnyaya \\ Krasnoselskaya str., 17. \\ RUSSIA \\ N.V. VASHUKEVICH \\ Department of Land \\ Management \\ Ural State Agrarian \\ University \\ 620075, Ekaterinburg, Karl \\ Liebknecht str., 42 \\ RUSSIA
}

\author{
E.A. SKVORTSOV \\ Department of Competition Law \\ and Antimonopoly Regulation \\ Ural State Economic University \\ Ekaterinburg, March 8 str. \\ RUSSIA \\ Y.V. MALKOVA \\ Department of Accounting \\ and audit \\ Ural State Agrarian University \\ 620075, Ekaterinburg, Karl \\ Liebknecht str., 42 \\ RUSSIA
}

Abstract: - In 2018, only 1\% of industry organizations use digital technologies, which reduces the competitiveness of Russian agriculture significantly. The relevance of the research topic is due to the low rates of implementation of precision farming technologies in agricultural production. The study aims to assess the motivational aspects and analyze the factors that promote and hinder the implementation and use of precision farming technologies by farmers. To achieve the goal and objectives of the study, a survey of farmers in the Sverdlovsk and Kurgan regions, as well as of employees of agricultural organizations was carried out. According to the survey results, the most favorable factors contributing to the implementation and use of precision farming technologies are the level of efficiency of agricultural production and the need to improve it; state support for their implementation; the level of development of the precision farming technologies market. The limiting factors for the implementation and use of precision farming technologies are the unsatisfactory financial conditions of a significant part of farmers, a high level of prices for precision farming technologies in comparison with traditionally used equipment, and poor availability of the personnel capable of mastering precision farming technologies. It should be noted that farmers are highly motivated to implement and use precision farming technologies, which are treated as an objective necessity, causing significant positive changes in agriculture in the nearest future. This allows us to conclude that there is a low level of workers' resistance to the implementation of these technologies.

Key-Words: - precision farming, precision farming technologies, factors, motivation, agricultural organizations

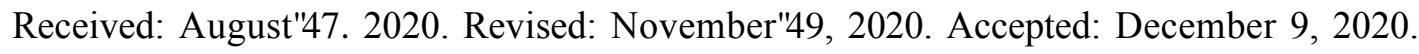

Published: December 16, 2020.

\section{Introduction}

It is important to determine the conditions for the application of these technologies in agriculture. According to the hypothesis of
Norton and Swinton [1], the precision farming technologies will be primarily applied at big farms with large capital investment per hectare [2]. Therefore, as a main scientific hypothesis, 
it can be assumed that the implementation of precision farming technologies will take place mainly at large agricultural organizations, as this may require additional financing for purchasing and controlling a large machinery fleet or agricultural lands [3].

According to several Russian researchers, Afanasyev and others, "precision farming is based on the capabilities of modern geoinformation systems, which allow quick online determining the coordinates of working agricultural machines and, thus, regulating technological modes in accordance with specific conditions at particular points and some field areas" [4]. Zhukova O. believes that precision farming is a technology with all agrotechnical activities with consideration of characteristics of individual field areas with different agrochemical and agrophysical indicators, the relief and individual approaches to cultivation, i.e. differentiated sowing, fertilization and plant protection products with minimal errors [5].

Experts estimate the global precision farming market to be worth $\$ 4.73$ billion in 2019 and is expected to reach $\$ 5.47$ billion in 2020. At the same time, the volume of the global market for precision farming technologies will increase by an average of $13.0 \%$ per year in the period from 2020 to 2027 and will amount to more than $\$ 12.8$ billion in 2027. At the same time, the scientific sources available in well-known bibliographic databases mainly describe the technical and technological aspects of precision farming, which indicates the insufficient development of the problem of the development of fundamental scientific knowledge concerning scientific approaches, methodology and tools for the introduction and application of precision farming technologies in agricultural production, which have an important social -economic and political significance.

A low share of agricultural organizations using precision farming technologies is pointed out in the concept "Scientific and technological development of digital agriculture "Digital agriculture" developed by such authoritative organizations as the Russian Academy of Sciences, Moscow State University by M.V.
Lomonosov, "Higher School of Economics" and others under the leadership of the Ministry of Agriculture of the Russian Federation. It is stated that the share of agricultural enterprises using technologies of the Internet of Things, precision farming, digital herds and smart greenhouses at the end of 2018 is less than $1 \%$. At the same time, the target indicators show an ambitious task to increase this indicator in 20 times by 2021, and in 60 times by 2024 .

\section{Problem Formulation}

The available scientific literature sources mainly describe the technical and technological aspects of precision farming, but lack the development of theoretical moments for the application of precision farming technologies in agricultural production. At the same time, the theoretical issues of applying precision farming technologies have been studied poorly, and that is a relevant scientific problem. So, the analysis of factors which promote and hinder the implementation of precision farming technologies at agricultural organizations is a crucial problem.

The study aims to assess the motivational aspects and analyze the factors that promote and hinder the implementation of precision farming technologies at agricultural organizations.

To achieve the goal, the following research tasks can be distinguished:

- to conduct a survey of experts-managers and specialists of agricultural organizations, managers and specialists of territorial agricultural management bodies about the factors promoting and hindering the implementation of precision farming technologies;

- to carry out an average and relative assessment of relevance of factors promoting and hindering the implementation of precision farming technologies;

- to assess the motivational aspects of the activities of managers and specialists at agricultural organizations to the use of precision farming technologies;

- to assess the possible resistance of workers to the implementation of precision farming technologies.

A relevant methodology with several stages 
is applied to determine the factors promoting and hindering the implementation of precision farming technologies, The first stage involves a survey of experts-managers and specialists at agricultural organizations (farmers), managers and specialists of territorial agricultural management bodies. This survey was carried out in a region with a high rate of implementation of precision farming technologies according to the Ministry of Agriculture of the Russian Federation, the Kurgan region. The survey was also conducted in the Sverdlovsk region, it was taken as a control region with a low rate of technologies implementation. This will highlight the factors that promote and hinder the implementation of precision farming technologies. The surveys will propose to assess the relevance of factors at a 10-point scale. Then, an average assessment of significance of the $\mathrm{Fi}$ factor will be calculated, which will be the arithmetic mean of the assessments of all experts. Then, a relative assessment of significance of the $\mathrm{Zi}$ factor will be calculated, as a ratio of the average assessment of significance of each factor to the sum of the average assessments of significance of all factors. Each factor will get significance ranks. At the final stage, it is planned to compare the results of assessing the factors that promote and hinder the implementation of precision farming technologies of two surveyed groups (regions with high and low rates of implementation of these technologies).

There was a survey of managers and specialists of organizations in the Sverdlovsk region to study the motivational aspects, awareness and expectations of managers and specialists of agricultural organizations concerning precision farming technologies.

We consider it necessary to develop and use a methodology for assessing the factors of implementation and use of precision farming technologies. The methodology is a comprehensive assessment of the advantages and disadvantages that promote and hinder the implementation and use of precision farming technologies.

The assessment of the factors influencing the implementation and use of precision farming technologies was carried out according to the following method:

1. An assessment of the factors degree was carried out by experts on a 10-point scale.

2. An average assessment of the significance of the factors $F_{i, h}$ was determined as the arithmetic mean of all assessments of all managers and specialists of agricultural organizations according to the formula:

$$
\mathrm{F}_{\mathrm{i}, \mathrm{h}}=\frac{\sum_{\mathrm{n}=1}^{\mathrm{l}}(\mathrm{F})_{\mathrm{n}} * \mathrm{Zp}}{\mathrm{R}},
$$

where $F_{i, h}$ - is the assessment of the $i$ factors by a h-specialist-expert on a 10-point scale, points;

$\mathrm{i}-$ is the ordinal number of the expert, $\mathrm{n}=1$, ... 1;

$\mathrm{Zp}-$ is a relative assessment of the significance of factors influencing the implementation and use of precision farming technologies;

$\mathrm{R}$ - is a number of specialists-experts in a group, people;

1 - is a number of factors influencing the implementation and use of precision farming technologies, $1=1, \ldots 1$.

3. The relative assessment of the significance of $\mathrm{Zi}$ factor is determined as a ratio of the average assessment of the significance of each factor to the sum of the average assessments of the significance of all factors according to the formula:

$$
F=\frac{\mathrm{Z}_{\mathrm{l}}}{\sum_{\mathrm{l}=1}^{\mathrm{i}} \mathrm{Z}_{\mathrm{l}}}
$$

where $1-$ is a total number of factors influencing the implementation and use of precision farming technologies.

The average $\mathrm{F}$ and relative $\mathrm{Z}$ estimates of factors with $S$-index refer to the Sverdlovsk region, and with the K-index - to the Kurgan region.

The characteristics of the respondents engaged in the survey are of great importance for ensuring the representativeness of the research results. In particular, a survey of farmers in the Sverdlovsk and Kurgan regions was conducted to assess the factors and motivation for the implementation of precision farming technologies. In terms of age, the largest share is people of 51 and over, that is 16 
people (36.4\% of the respondents), at the age of $41-50-12$ respondents $(27.3 \%)$, at the age of $31-40$ - 10 people $(22.7 \%)$.

The smallest share $(12.7 \%)$ is young people under 30; that is 7 people. Thus, all age groups are represented in the study that allows avoiding distortions in the results of the questionnaire by age. In the structure of the surveyed farmers by gender, males occupy the largest share. Their share is $54.5 \%$, and the share of women is $45.5 \%$. This eliminates deformations due to differences in motivational preferences by gender.

\subsection{Assessment of factors influencing the introduction and use of precision farming technologies}

The largest number of precision farming technologies in agriculture in the Middle Urals refers to satellite monitoring of vehicles $(80.1 \%)$, parallel driving systems $(13.2 \%)$, determination of land boundaries (4.8\%). Satellite vehicle monitoring is widely used in agriculture to control the movement of vehicles and control production over large areas. In agriculture of the Middle Urals, satellite monitoring of vehicles is carried out using GNSS based on the Glonass system. Satellite receivers are installed on vehicles, including tractors, harvesters, buses and trucks, which allows monitoring the movement of these vehicles. Parallel driving systems are widely used on combines and tractors to reduce driver errors by pinpointing position in the field (which is often difficult to pinpoint visually) and compensating for driver fatigue. Determining the boundaries of fields using satellite navigation systems allows you to get up-to-date data on the size of land plots. The following satellite receivers can be used to determine the field boundaries: Glonass "WialonHosting, Glonass Trimble ES 250; Glonass "Wialonloka 1" and many others. Thus, in most cases, built-in sensors are used attached to equipment (tractors, combines, etc.), as well as optical sensors, smart cameras, GPS sensors and other devices.

An important issue is the assessment of the factors influencing the introduction and use of precision farming technologies. For example, a study conducted in the Netherlands [7] in 2014 indicated the presence of a wide range of stakeholders as one of the decisive factors. These include various associations of farmers, resource providers, retailers and consumers, researchers, politicians, etc. The level of infrastructure development, including the Internet in rural areas, is of great importance.

The assessment of factors significance influencing the implementation and use of precision farming technologies in the Middle Urals was carried out with involvement of managers and specialists of agricultural organizations (farmers) as experts (Table 1).

Table 1. Assessment of factors influencing the implementation and use of precision farming technologies (the results of the survey of experts)

\begin{tabular}{|c|c|c|c|c|c|c|}
\hline $\begin{array}{c}\text { Factors influencing the } \\
\text { implementation and use of } \\
\text { precision farming technologies }\end{array}$ & $\begin{array}{c}\text { Average } \\
\text { assessment } \\
\text { of } \\
\text { significance } \\
\mathrm{F}_{\mathrm{iS}}\end{array}$ & $\begin{array}{c}\text { Relative } \\
\text { assessment } \\
\text { of } \\
\text { significance } \\
\mathrm{Z}_{\mathrm{iS}}\end{array}$ & $\begin{array}{c}\text { Rank } \\
\text { of } \\
\text { signific } \\
\text { ance }\end{array}$ & $\begin{array}{c}\text { Average } \\
\text { assessment } \\
\text { of } \\
\text { significance } \\
\mathrm{F}_{\mathrm{iK}}\end{array}$ & $\begin{array}{c}\text { Relative } \\
\text { assessment } \\
\text { of } \\
\text { significance } \\
\mathrm{Z}_{\mathrm{iK}}\end{array}$ & $\begin{array}{c}\text { Rank } \\
\text { of } \\
\text { significa } \\
\text { nce }\end{array}$ \\
\hline $\begin{array}{c}\text { Development level of precision } \\
\text { farming technologies market }\end{array}$ & 7,44 & 0,559 & 3 & 6,47 & 0,668 & 4 \\
\hline $\begin{array}{c}\text { Availability and state support } \\
\text { level for implementation of } \\
\text { precision farming technologies }\end{array}$ & 7,68 & 0,577 & 2 & 7,53 & 0,777 & 2 \\
\hline $\begin{array}{c}\text { Developed infrastructure for } \\
\text { ensuring implementation of } \\
\text { precision farming technologies }\end{array}$ & 6,08 & 0,456 & 6 & 5,89 & 0,608 & 7 \\
\hline $\begin{array}{c}\text { Competition level among } \\
\text { agricultural organizations }\end{array}$ & 5,32 & 0,399 & 8 & 4,16 & 0,429 & 8 \\
\hline $\begin{array}{c}\text { Efficiency level of agricultural } \\
\text { production and necessity to }\end{array}$ & 8,08 & 0,607 & 1 & 8,21 & 0,847 & 1 \\
\hline
\end{tabular}




\begin{tabular}{|c|c|c|c|c|c|c|}
\hline improve it & & & & & & \\
\hline $\begin{array}{l}\text { Ecological friendliness of } \\
\text { agricultural production and } \\
\text { necessity to improve it }\end{array}$ & 6,36 & 0,477 & 5 & 5,95 & 0,614 & 6 \\
\hline $\begin{array}{l}\text { Moral encouragement and } \\
\text { public recognition of } \\
\text { agricultural organizations } \\
\text { implementing precision farming } \\
\text { technologies } \\
\end{array}$ & 5,48 & 0,411 & 7 & 6,16 & 0,635 & 5 \\
\hline Top management interests & 6,84 & 0,514 & 4 & 6,63 & 0,684 & 3 \\
\hline
\end{tabular}

According to the respondents, the implementation and use of precision farming technologies, first of all, can be promoted by the efficiency level of agricultural production and need of its improvement. This correlates with the study results of various research groups of scientists. So, Lambert D. testifies that the use of precision farming technologies has a positive effect in $63 \%$ of cases, while a negative result only in $11 \%$ and an undefined result in $26 \%$ [6]. In particular, the use of a differentiated fertilizer application system in combination with the analysis of land plots can reduce the cost of production by $6-9 \%$. Thus, farmers are interested in using these technologies, as this allows them, first of all, to increase production efficiency. At the same time, in the Sverdlovsk region, the average assessment of significance of this factor was 8.08, and the relative assessment was 0.607 points. In the Kurgan region, the average assessment of significance of production efficiency was 8.34 points, and the relative assessment was 0.834 points.

The availability and level of state support in implementation and use of precision farming technologies is the second most significant factor influencing the implementation of these technologies. The average assessment of significance of this factor was 7.68 and the relative assessment was 0.577 points in the Sverdlovsk region and, 7.53 and 0.777 points in the Kurgan region respectively. It should be noted that the technical re-equipment of agriculture, including the implementation of precision farming technologies, is associated with significant capital investments. However, the financial capacities of Russian farmers are limited. This necessitates appropriate support from government authorities. For example, up to $30 \%$ of the budget is spent on supporting farmers in the European Union [7]. It can be assumed that an increase in subsidies to farmers results in an increase in the level of technical equipment. However, this assumption requires a further study.

According to the farmers, a significant factor influencing the implementation and use of precision farming technologies is the level of development of these technologies market. The average assessment of significance of this factor was 7.44, and the relative assessment was 0.559 points in the Sverdlovsk region. Indeed, the market of agricultural technologies, including precision farming technologies, is developing rapidly. According to some estimates, the growth rate of the market of new agricultural technological solutions is higher than in such high-tech industries as industrial production. It is curious that the significance of this factor in the Kurgan region is lower than in the Sverdlovsk region.

The average assessment of significance of the "Top management interest" factor was 6.84, and the relative assessment was 0.514 points in the Sverdlovsk region. This may be due to the adoption of a number of programs aimed at the innovative development of agriculture. This may include the Resolution of the Government of the Russian Federation "On approval of the Federal Scientific and Technical Program for Development of Agriculture for 2017 - 2025". It sets out the tasks on development and implementation of modern production technologies, processing and storage of agricultural products, raw materials and food; improvement of the system of training and additional vocational education of personnel for the agro-industrial complex, focused on rapid adaptation to the requirements of scientific and 
technological progress. Another significant project in this direction is the departmental project "Digital Agriculture". In accordance with this project, an approach to the digital transformation of agriculture is considered through the implementation of digital technologies and platform solutions to ensure a technological breakthrough in the agroindustrial complex and achieve productivity growth at "digital" agricultural enterprises.

The implementation and use of precision farming technologies is significantly influenced by the level of environmental friendliness of production. The farmers in the Sverdlovsk region give 6.36 as the average assessment of significance of this factor, and the relative assessment is 0.477 points. The significance of this factor in the Kurgan region is lower (5.95 and 0.0614 points, respectively), which indirectly may indicate a lesser interest of the regional farmers in solving environmental problems.

An important issue is to determine the factors that hinder the implementation and use of precision farming technologies. A comprehensive assessment of these factors is presented in Table 2.

Table 2. A comprehensive assessment of shortcomings, implementation and use of precision farming technologies (results of the survey of experts)

\begin{tabular}{|c|c|c|c|c|c|c|}
\hline $\begin{array}{c}\text { Factors hindering the implementation } \\
\text { and use of precision farming } \\
\text { technologies }\end{array}$ & $\begin{array}{c}\text { Average } \\
\text { assessment } \\
\text { of } \\
\text { significanc } \\
\text { e Fis }\end{array}$ & $\begin{array}{c}\text { Relative } \\
\text { assessment } \\
\text { of } \\
\text { significance } \\
\mathrm{Z}_{\text {is }}\end{array}$ & $\begin{array}{l}\text { Rank of } \\
\text { significa } \\
\text { nce }\end{array}$ & $\begin{array}{c}\text { Average } \\
\text { assessment } \\
\text { of } \\
\text { significance } \\
\mathrm{F}_{\mathrm{iK}}\end{array}$ & $\begin{array}{c}\text { Relative } \\
\text { assessment } \\
\text { of } \\
\text { significanc } \\
\text { e } \mathrm{Z}_{\mathrm{iK}}\end{array}$ & $\begin{array}{l}\text { Rank of } \\
\text { significa } \\
\text { nce }\end{array}$ \\
\hline $\begin{array}{l}\text { Financial state of agricultural } \\
\text { organizations }\end{array}$ & 7,96 & 0,698 & 1 & 7,63 & 0,784 & 1 \\
\hline $\begin{array}{l}\text { Payback period from the } \\
\text { implementation of precision farming } \\
\text { technologies }\end{array}$ & 5,16 & 0,452 & 5 & 5,53 & 0,568 & 5 \\
\hline $\begin{array}{l}\text { The level of industrial and general } \\
\text { culture }\end{array}$ & 5,24 & 0,459 & 4 & 5,68 & 0,584 & 4 \\
\hline $\begin{array}{l}\text { The level of development of modern } \\
\text { infrastructure (Internet, roads, etc.) }\end{array}$ & 4,44 & 0,389 & 7 & 5,11 & 0,525 & 6 \\
\hline The rate of technological changes & 3,96 & 0,347 & 8 & 4,21 & 0,433 & 8 \\
\hline $\begin{array}{lcr}\text { Availability } & \text { of personnel at } \\
\text { agricultural } & \text { organizations capable of } \\
\text { mastering } & \text { precision } & \text { farming } \\
\text { technologies } & & \end{array}$ & 7,36 & 0,645 & 2 & 6,53 & 0,671 & 3 \\
\hline $\begin{array}{l}\text { Price level for precision farming } \\
\text { technologies in comparison with } \\
\text { traditionally used equipment }\end{array}$ & 7,04 & 0,617 & 3 & 6,95 & 0,714 & 2 \\
\hline $\begin{array}{l}\text { Orientation to traditional (simple) } \\
\text { technologies }\end{array}$ & 4,48 & 0,393 & 6 & 4,53 & 0,465 & 7 \\
\hline
\end{tabular}

According to the survey, the most serious obstacle to the implementation and use of precision farming technologies is the financial conditions of agricultural organizations. This may be due to the fact that a significant part of farmers in the Middle Urals have financial difficulties. So, the analysis of the production and financial activities of agricultural organizations in the Sverdlovsk region shows that 41 organizations (or $17.6 \%$ of their total number) ended 2019 year with a loss. It should be noted that in 2018 this number was 34 organizations. At the same time, the level of profitability of agricultural organizations in 2019 was $8.5 \% \quad(10.7 \%$ in 2018). The unsatisfactory financial conditions of a significant proportion of farmers can serve as an obstacle to updating the material and technical base, including the implementation of precision farming technologies. According to the farmers, 
the average assessment of significance of this factor was 7.96, and the relative assessment was 0.698 points in the Sverdlovsk region and 7.63 and 0.784 points in the Kurgan region.

Another significant factor hindering the implementation and use of precision farming technologies is the availability of personnel at agricultural organizations, which is capable to master precision farming technologies. While training personnel for the implementation and application of precision farming technologies, it is of great importance to have the required number of stands simulating the operations of this machinery, computer equipment and software and the corresponding infrastructure. However, the material and technical base of many educational institutions does not meet the modern level of production, the educational process is conducted with outdated equipment.

The modernization of outdated teaching and laboratory equipment is not being carried out intensively enough. Many engineering departments at agricultural colleges and institutes do not have classrooms and laboratories with modern equipment, computer technologies, which allow modeling and using high-performance software. Educational institutions are equipped mainly with machinetool equipment, removed from the armament of machine-building plants. Students need educational and training-experimental farms to get practical skills while studying precision farming technologies. The quality of educational and research work depends on the level of their development, technical equipment, and organization of labor. However, a significant part of educational institutions still do not have educational facilities, many of them are equipped with outdated tractors and agricultural machines of the previous generation and lack skilled specialists. So, many graduates of educational institutions meet new robotic, intelligent equipment and technologies of precision farming only at agricultural organizations. According to the farmers of the Sverdlovsk region, the average assessment of significance of this factor was 7.36, and the relative assessment was 0.645 points. It should be noted that the value of this factor in the Kurgan region was lower and was 6.53 and 0.671 points.

Farmers in the Middle Urals are greatly concerned about the level of prices for readymade solutions and elements of precision farming in comparison with traditionally used equipment and technologies. According to the survey, the average assessment of this factor in the Sverdlovsk region was 7.04 points, and the relative assessment was 0.617 points. At the same time, in the Kurgan region, this factor takes the second place in significance (the average assessment was 6.95 , the relative one was 0.714 points). The high significance of this factor is influenced by the fact that almost all used electronics in these technologies are not produced in the Russian Federation. After the growth of the exchange rate, there was a sharp rise in prices for these products. This has a negative impact on the dynamics of implementation and use of precision farming technologies.

\subsection{Assessment of motivational aspects}

An assessment of the motivational aspects of the activities of managers and specialists of agricultural organizations (farmers) to the use of precision farming technologies is presented in Figure 1. 


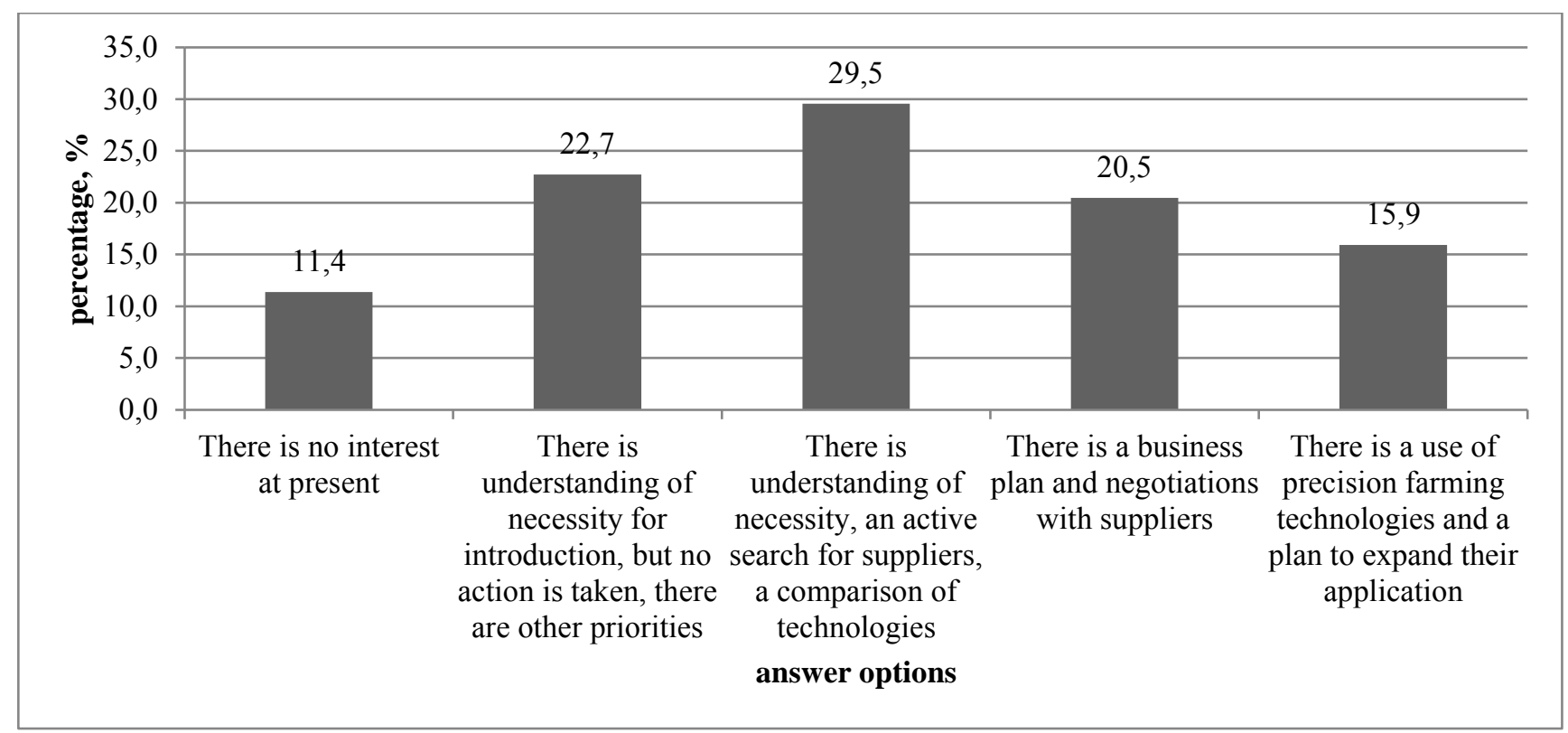

Figure 1. Motivational aspects of the activities of managers and specialists of agricultural organizations to the use of precision farming technologies

The largest share of the surveyed farmers $(29.5 \%)$ understands the need to apply precision farming technologies and they are looking for suppliers, comparing various options for technologies. At the same time, a significant proportion of farmers $(20.5 \%)$ is currently negotiating with suppliers and has a business plan. A certain proportion of farmers $(15.9 \%)$ of the respondents already use precision farming technologies and plan to expand their use. Our earlier studies allow us to conclude that 49 business entities (farmers) of the Sverdlovsk Region use precision farming technologies. This is $21 \%$ of all agricultural organizations (farmers), which, in terms of the number of staff, 8 can be attributed to micro-business, 10 to small business, 17 to medium-sized business and 11 to large-scale entrepreneurship [8]. It should be noted that only $11.4 \%$ of farmers in the Sverdlovsk region are not interested in the use of precision farming technologies at the present time, and $22.7 \%$ of farmers understands the need for application, but do nothing as they have other priorities.

\subsection{Assessment of possible resistance of workers}

It is important to assess the potential resistance of workers to the implementation of precision farming technologies. This may be due to the fact that any significant change in established working methods causes resistance at all categories of workers, both ordinary performers and managers. As A.N. Lyukshinov noted in his work, "resistance is a natural reaction of groups and individuals to changes that threaten their culture and influence, and is caused by a violation of the continuity of culture and power; its strength depends on the rate of increase of changes" [9]. According to the authors of the popular textbook "Fundamentals of Management" M.Kh. Mescon, M.Albert and F.Hedoury, people resist changes for three main reasons: because of uncertainty, the emergence of a sense of loss and the belief that changes will not bring anything good [10]- [12]. In accordance with the objectives of the study, a survey of workers of agricultural organizations was conducted; the results are presented in Figure 2. 


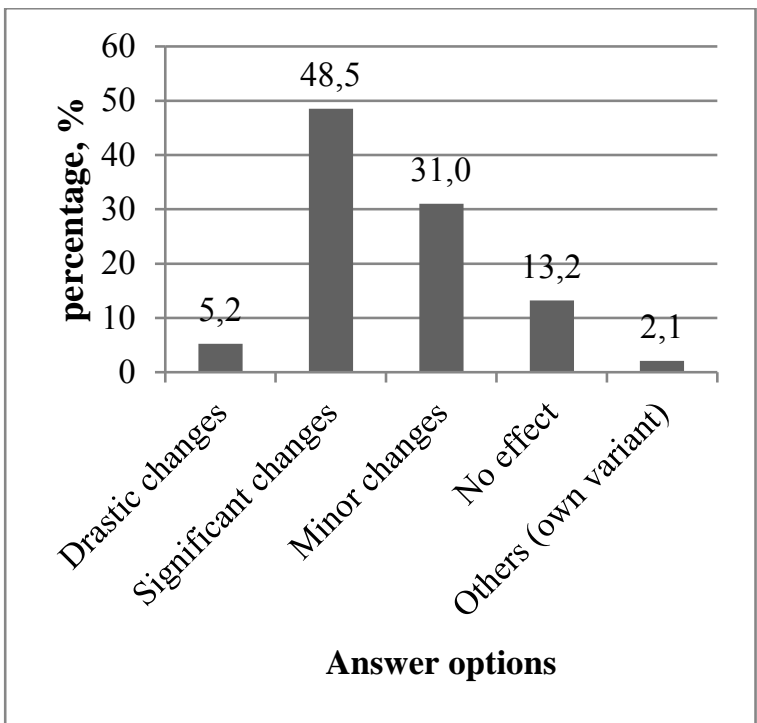

Figure 2. Workers' expectations regarding the changes caused by the implementation of precision farming technologies

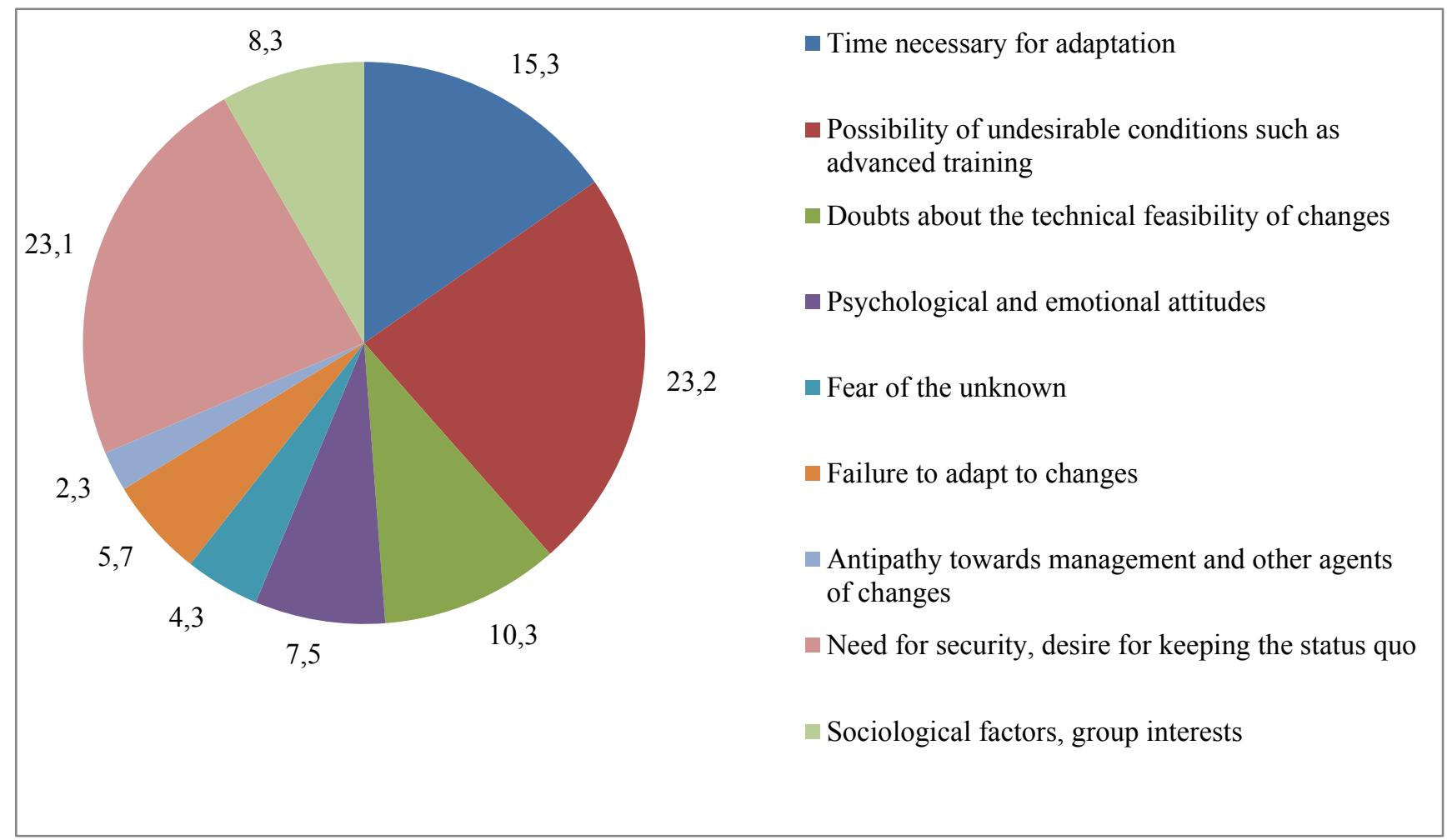

Figure 3. Forms of workers' resistance to the implementation of precision farming technologies

According to the survey, the most common (23.1\%) form of workers' possible resistance to the implementation of precision farming technologies is the possibility of making undesirable conditions. Most often this may be due to the need for advanced training. A significant part of employees $(23.1 \%)$ have a need for safety and a desire to maintain the status quo. About $15.3 \%$ of the surveyed
According to the survey of agricultural workers, the largest part of them (48.5\%) expects significant changes as a result of the application of precision farming technologies in the industry. At the same time, only $13.2 \%$ believes that their application will not affect the development of the industry.

The forms of workers' resistance to the implementation of precision farming technologies are presented in Figure 3.
Antipathy towards management and other agents
of changes

Need for security, desire for keeping the status quo

workers spoke about the need to provide time for adaptation to these technologies. Only an insignificant part of employees (10.3\%) have doubts about the technical feasibility of changes.

\section{Conclusion}

According to the results of the survey of farmers, the most favorable factors contributing 
to the implementation and use of precision farming technologies are the level of agricultural production efficiency and the need to improve it. However, in farmers' opinion, the state support for the implementation of precision farming technologies and the level of development of the precision farming technologies market should be increased. The limiting factors for the implementation and use of precision farming technologies are unsatisfactory financial conditions of a significant part of the farms, a high level of prices for precision farming technologies in comparison with the traditionally used equipment, and low availability of personnel capable of mastering precision farming technologies at agricultural organizations. Nowadays in Russia training of the personnel for agriculture is carried out according to outdated educational programs and with a lagged material and technical base at educational institutions (colleges and universities). It is important to note that in the region with a high level of implementation and use of precision farming technologies (the Kurgan region), the availability of personnel, in farmers' opinion, is less important than that of farmers in the Sverdlovsk region. The Sverdlovsk Region is an industrially developed region of Russia. At the same time, high-paying job positions in the industry attract skilled workers, which make a shortage of personnel in agriculture.

It should be noted that farmers are highly motivated to implement and use precision farming technologies. The vast majority of farmers treat these technologies as an objective necessity, which will cause significant positive changes in agriculture in the nearest future. Only $11.4 \%$ of farmers are not interested in precision farming technologies.

This correlates with employees' expectations, nearly half of those surveyed respondents believe that these technologies will result in significant changes. Many of them $(23.2 \%)$ expect the need for advanced training. However, a significant part of employees $(23.1 \%)$ indicate a need for security and a desire to maintain the status quo. About $15.3 \%$ of the surveyed workers speak about the need to provide time to adapt to these technologies. This allows us to conclude that the level of resistance of workers to the implementation of precision farming technologies is low.

\section{Acknowledgments/ Financing}

The study was funded by RFBR, a project number is №20-010-00827A "Research of theoretical aspects of the application of precision farming technologies in agricultural production".

References:

[1] Norton G., Swinton S. Precision Agriculture: Global Prospects and Environmental Implications /http://ageconsearch.umn.edu/record/19720 7/files/agecon-024conf-1997-016.pdf. 2000, pp. 18 doi.10.22004/ag.econ.197207

[2] Casa, R., \& Castrignanò, A., Analysis of spatial relationships between soil and crop variables in a durum wheat feld using a multivariate geostatistical approach, European Journal of Agronomy, 28(3), 2008, pp. 331-342

[3] Basso, B., Ritchie, J. T., Cammarano, D., \& Sartori, L., A strategic and tactical management approach to select optimal $\mathrm{N}$ fertilizer rates for wheat in a spatially variable feld, European Journal of Agronomy, 35(4), 2011, pp. 215-222

[4] Afanasyev R.A., Agrokhimicheskoye obespecheniye tochnogo zemledeliya, Problemy agrokhimii $i$ ekologii, Vol. 3, 2008, pp. 46-52.

[5] Zhukova, O., Tochnoye zemledeliye za rubezhom i v Rossii, Tekhnika $i$ oborudovaniye dlya sela, Vol., 12, 2008, pp. $26-28$

[6] Concept "Scientific and technological development of digital agriculture" Digital agriculture

"http://www.viapi.ru/download/2018/Digita $1 \% 20$ agriculture $\% 20 . p d f$

[7] Kempenaar C., Overview of topics and questions to be addressed by the FG Mainstreaming Precision Farming, Starting paper for $F G, 2014$. pp. 9.

[8] Lambert, D., and J. Lowenberg-DeBoer. 2001. "Precision Farming Profitability 
Review." Site-Specific Management Center. West Lafayette, IN: Purdue University. Available online at http://mollisol.agry.purdue.edu/SSMU/ (accessed February 2, 2001)

[9] Altukhov A.I., Semin A.N., Semenova E.I., Kislitsky M.M., Borodkin A.E. The agrifood sector of Russia in the face of "big challenges": problems, risks, new opportunities, Moscow - Publishing house: Fund "Personnel reserve", 2019, pp. 416

[10] Gusev A., Skvortsov E., Application of precision farming technologies in the Sverdlovsk region, Bulletin of Michurinsky State Agrarian University, No. 4 (63), 2020

[11] Lyukshinov A.N., Strategic management: Textbook for universities, M.:UNITYDANA, 2001

[12] Mescon M.Kh., Albert M., Hedouri F. Fundamentals of management: Trans. from English. M.: Delo, 2000

Contribution of individual authors to writing of the scientific article (ghostwriting policy): A. S. GUSEV, Developed a research methodology. E.A. SKVORTSOV, O.I. BETIN has performed calculations of section $2 . \quad$ N.V. ZIABLITCKAIA, N. VASHUKEVICH conducted a survey of farmers and processed information

Follow: www.wseas.org/multimedia/contributorrole-instruction.pdf
Creative Commons Attribution License 4.0 (Attribution 4.0 International, CC BY 4.0)

This article is published under the terms of the Creative Commons Attribution License 4.0

https://creativecommons.org/licenses/by/4.0/deed.en_US 